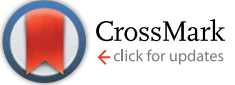

Cite this: RSC Adv., 2017, 7, 10361

Received 9th October 2016

Accepted 24th January 2017

DOI: 10.1039/c6ra24971j

rsc.li/rsc-advances

\section{Dithizone-etched CdTe nanoparticles-based fluorescence sensor for the off-on detection of cadmium ion in aqueous media}

\begin{abstract}
Li Li, ${ }^{\star}$ Lanfeng Liao, Yaping Ding* and Hongyan Zeng
In the present study, a new fluorescence probe based on dithizone-etched CdTe nanoparticles was designed for the sensitive and selective detection of cadmium ions in environmental samples via a reversible off-on fluorescence mode. At first, the initial bright fluorescence of L-cysteine-capped CdTe NPs could be effectively quenched in the presence of dithizone (DZ) due to the chemical etching effect, which results from the breaking of Cd-thiol layers by DZ, thus leading to a decrease in the NPs surface passivation. Then, upon the addition of $\mathrm{Cd}^{2+}$, the weak fluorescence of the CdTe NPs-DZ system gradually recovered, owing to the occurrence of $\mathrm{Cd}$-thiol passivation layers on the surface of the NPs. Under optimal conditions, a good linear relationship was obtained in the range from $0.4 \mu \mathrm{M}$ to $15.4 \mu \mathrm{M}$ for $\mathrm{Cd}^{2+}$, with a detection limit of $0.13 \mu \mathrm{M}$. In addition, this CdTe NPs-based nanosensor presents remarkable selectivity for $\mathrm{Cd}^{2+}$ over other metal ions and was successfully applied for the detection of $\mathrm{Cd}^{2+}$ in real water samples with satisfactory results, demonstrating its potential application for the determination of $\mathrm{Cd}^{2+}$ in the environment.
\end{abstract}

\section{Introduction}

Owing to their non-biodegradability, heavy metals are one of the most hazardous classes of pollutants in water sources, which have caused widespread water pollution, fish contamination, and serious health problems. ${ }^{1,2}$ As one of the most prevalent toxic metals in the environment, cadmium ion $\left(\mathrm{Cd}^{2+}\right)$ is widely present in air, soil, sediment, and water and can accumulate in the kidney, lung, liver, and bones of human beings with a long biological half-life of 20-30 years. ${ }^{3,4}$ Moreover, even at very low concentrations, $\mathrm{Cd}^{2+}$ can induce a wide variety of health issues including the major killer diseases such as heart disease, cancer, and diabetes. ${ }^{5-10}$ Inevitably, it is highly important to explore efficient methods for monitoring cadmium both in environment and in vivo.

Several analytical techniques, including atomic adsorption spectrometry (AFS), ${ }^{\mathbf{1 1}, 12}$ inductively coupled plasma mass spectroscopy (ICP-MS), ${ }^{13,14}$ and electrochemical methods, have been established for the determination of $\mathrm{Cd}^{2+} \cdot{ }^{15-17}$ Although these techniques generally provide high selectivity and sensitivity, they always require expensive and sophisticated instruments, complicated sample preparation, trained personnel, and high-cost, which limit their wide application. Therefore, there is a need to develop selective, sensitive, facile, rapid, and inexpensive approaches for the determination of cadmium ions. The use of

Department of Chemistry, Shanghai University, Shanghai, 200444, P. R. China. E-mail: lilidu@shu.edu.cn; wdingyp@sina.com; Fax: +86-21-66132797; Tel: +86-2166134734 a fluorescence probe is an alternative detection method that has the appealing advantages of high sensitivity, operational simplicity, and cost-effectiveness for the trace metal analysis. To date, a large number of fluorescent probes based on synthetic organic dyes for the determination of $\mathrm{Cd}^{2+}$ have been designed. ${ }^{18,19}$ Sil et $a .^{18}$ developed a phenylene-vinylenefunctionalized terpyridine conjugate-based turn-on fluorescent probe for the detection of $\mathrm{Cd}^{2+}$ in the submicromolar level. Visscher et al. ${ }^{19}$ reported a new fluorescence sensor for $\mathrm{Cd}^{2+}$ and $\mathrm{Zn}^{2+}$ based on a new acridine derivative. However, some shortcomings, such as relatively complicated synthesis and purification processes, low-fluorescence quantum yields, poor water solubility, use of biologically toxic solvents (MeCN, DMSO, and DMF), and weak resistance to photobleaching, still exist among these probes.

Compared to traditional organic dyes, colloidal semiconductor nanoparticles (also referred to as quantum dots, QDs) possess a series of merits such as broad excitation and size-tunable emission spectra, low-cost, simple synthetic routes, relatively high quantum yields (QYs), and photochemical stability. Due to these properties, semiconductor nanoparticles are widely used as fluorescent nanosensors for the detection of metal ions (such as $\mathrm{Cd}^{2+}, \mathrm{Cu}^{2+}, \mathrm{Pb}^{2+}, \mathrm{Hg}^{2+}$, and $\mathrm{Fe}^{3+}$ ), ${ }^{20-24}$ small molecular substances (for example, AA, melamine, and biothiol), ${ }^{25-27}$ protein/DNA, ${ }^{28,29} \mathrm{pH},{ }^{30,31}$ anions (for instance, $\mathrm{PO}_{4}{ }^{3-}$, $\mathrm{NO}_{2}{ }^{-}$, and $\left.\mathrm{CN}^{-}\right),{ }^{32-34}$ etc. by monitoring the changes in their fluorescence intensity. Recently, quantitative detection of heavy metal ions with semiconductor nanoparticles via spectral changes in photoluminescence has been extensively reported. The fluorescent chemosensors are based on some sensing 
mechanism such as photoinduced electron transfer (PET), fluorescence resonance energy transfer (FRET), and electronic energy transfer (EET). In general, they work only when they meet certain requirements such as when they have a complementary geometry or are at a particular distance. As a result, methods based on the abovementioned mechanisms are complicated and restrict practical applications. An alternative approach to design fluorescent sensors is based on the chemical etching effect, which originates from an etching reagent generating specific recognition sites on the surface of NPs for the selective turn-on detection of an absorber in the detection system. ${ }^{35}$ This method can achieve enhanced sensitivity compared to other methods. However, CdTe NPs-based fluorescent sensors using dithizone as the etching reagent for the simple detection of cadmium ion by turning the fluorescence on have not been developed.

Herein, we propose a new and facile fluorescent sensor based on a CdTe NPs-dithizone (DZ) system for the highly selective detection of $\mathrm{Cd}^{2+}$ in environmental samples. First, CdTe NPs were applied to detect DZ based on the chemical etching effect by a remarkable fluorescence quenching phenomenon. Then, the CdTe NPs-DZ mixture could behave as a turn-on fluorescent sensor for the determination of $\mathrm{Cd}^{2+}$. Moreover, this method presented high selectivity and sensitivity for $\mathrm{Cd}^{2+}$ over other common metal ions.

\section{Experimental}

\subsection{Reagents}

All chemicals were of analytical reagent grade and were directly used as received without further purification. Cadmium chloride $\left(\mathrm{CdCl}_{2} \cdot 2.5 \mathrm{H}_{2} \mathrm{O}, 99 \%\right)$, sodium borohydride $\left(\mathrm{NaBH}_{4}, 98 \%\right)$, tellurium powder (Te, 99.999\%, 100 mesh), L-cysteine (99\%), dithizone (DZ), ethanol, and other routine chemicals were purchased from Shanghai Sinopharm Chemical Reagent Co. Ltd. (China). Unless otherwise stated, ultrapure water was used for the preparation of all the solutions throughout the experiments. Lake water was obtained from Pan-chi in our university, and tap water was obtained from our lab.

\subsection{Apparatus}

Transmission electron microscopy (TEM) images of the L-cysteine-capped CdTe nanoparticles were acquired using a JEOL-200 CX transmission electron microscope (Japan). Size distribution of the particles was measured using a Zetasizer 3000HS Zeta potential/particle sizer (Malvern, UK). X-ray powder diffraction (XRD) spectra were obtained using a Rigaku D/max 2550 X-ray diffractometer equipped with $\mathrm{Cu} \mathrm{K} \alpha$ radiation $(\lambda=0.15418 \mathrm{~nm})$. Fourier transform infrared spectra (FT-IR) were obtained using an AVATAR 370 Fourier transform infrared spectrometer (America). A UV-2501PC spectrometer (Shimadzu, Japan) was used to acquire the ultraviolet visible (UV-vis) absorption spectrum. Lifetime measurements were carried out using a steady state and transient state fluorescence spectrometer (America). All fluorescence measurements were carried out using an RF-5301PC spectrofluorophotometer
(Shimadzu, Japan) equipped with a $1 \mathrm{~cm}$ path-length quartz cell and a xenon lamp with right-angle geometry.

\subsection{Synthesis of water-soluble L-cysteine-capped CdTe NPs}

Herein, based on the previous study, a modified method developed by our group was adopted to synthesize L-cysteinecapped CdTe NPs. ${ }^{36}$ Typically, $151.2 \mathrm{mg}$ (4 mmol) of $\mathrm{NaBH}_{4}$ and $25.5 \mathrm{mg}(0.2 \mathrm{mmol})$ of Te powder were added to a small flask, followed by the addition of $5 \mathrm{~mL}$ ultrapure water, where the air was pumped off and replaced with $\mathrm{N}_{2}$. The reaction mixture was heated at $26{ }^{\circ} \mathrm{C}$ to obtain a clear colourless solution. The obtained NaHTe solution was used as a Te precursor for further use.

Cd precursor solutions were prepared according to the following steps. First, $\mathrm{CdCl}_{2} \cdot 2.5 \mathrm{H}_{2} \mathrm{O}(91.3 \mathrm{mg}, 0.4 \mathrm{mmol})$ and $\mathrm{L}^{-}$ cysteine $(121.2 \mathrm{mg}, 1.0 \mathrm{mmol})$ were placed in a three-necked flask to form $95 \mathrm{~mL}$ homogeneous aqueous solution. Second, the $\mathrm{pH}$ value of the solution was adjusted to 9 by the dropwise addition of a $1.0 \mathrm{~mol} \mathrm{~L}^{-1} \mathrm{NaOH}$ solution. Under the protection of $\mathrm{N}_{2}$, a freshly prepared NaHTe solution was quickly poured into the abovementioned mixture (final molar ratio: $\mathrm{Cd}^{2+} / \mathrm{Te}^{2-} /$ L-cys $=1: 0.5: 2.5$ ). Then, the mixture solution was boiled for 7-8 $\mathrm{min}$ in an oil bath and refluxed in a water bath at $60^{\circ} \mathrm{C}$ for $1 \mathrm{~h}$. The molar concentration of the CdTe NPs solution was estimated to be around $25 \mu \mathrm{M}$ using the empirical mathematical functions reported by $\mathrm{Yu}$ et $a l .{ }^{37}$ The solution was stored in the dark for further experiments after was cooled down.

\subsection{Sample preparation for the PL quenching and enhancement}

For dithizone detection, a series of solutions were prepared as follows. First, we successively added $200 \mu \mathrm{L}$ of the as-prepared $\mathrm{L}^{-}$ cysteine-capped CdTe NPs solution and different concentrations of dithizone (DZ) ethanol solution (from 0 to $62 \mu \mathrm{M}$ ) to a set of dry $25 \mathrm{~mL}$ calibrated flasks, diluted them to the calibration mark by adding ultrapure water, and then completely mixed them under gentle stirring to obtain their fluorescence spectra after incubation for $40 \mathrm{~min}$. Eventually, we determined the optimal amount of dithizone (DZ) ethanol solution, which served as the fluorescence off reagent for further experiments.

To detect $\mathrm{Cd}^{2+}, 200 \mu \mathrm{L}$ L-cysteine-capped CdTe NPs stock solution and a certain volume of dithizone (DZ) ethanol solution were respectively added to a set of dry $25 \mathrm{~mL}$ calibrated flasks, and left to react for $40 \mathrm{~min}$ to finish the quenching process. Then, we added different concentrations of $\mathrm{Cd}^{2+}$ stock solution to the flasks, and thoroughly mixed them. All fluorescence measurements were performed under ambient conditions. The excitation and emission slit widths were $5 \mathrm{~nm}$, and the excitation wavelength was set at $328 \mathrm{~nm}$.

\section{Results and discussion}

\subsection{Characterization of the synthesized $L$-cysteine-capped CdTe NPs}

The morphology and structure of the L-cysteine-capped CdTe NPs were characterized via TEM and XRD. The TEM image 
(Fig. 1A) indicates that the CdTe NPs are close to regular spherical and dispersed well in the aqueous solution with an average size of around $80 \mathrm{~nm}$. Moreover, there are some linkages between the NPs, which visually reveal that L-cysteine was modified onto the NPs surface. Furthermore, we carried out the particle size measurement of the NPs using DLS equipment. As presented in Fig. 1B, the average size of the NPs is $137.4 \mathrm{~nm}$, which is observably larger than that predicted from TEM. This is because the DLS technique provides the mean hydrodynamic diameter of the NPs core surrounded by solvation layers, which can be influenced by the concentration and viscosity of the solution. ${ }^{38}$ The XRD pattern is depicted in Fig. 1B, which was scanned over the 2 theta $(\theta)$ range of $10-80^{\circ}$. There are three broad and distinct diffraction peaks at $23.76^{\circ}, 39.31^{\circ}$, and $46.43^{\circ}$, which correspond to the crystal planes of (111), (220), and (311), respectively. Furthermore, the position of the XRD peaks of the CdTe NPs matches well with that of a cubic zinc blend crystalline structure, according to the standard JCPDS data (card 15-0770). In addition, the EDS analysis shows strong atomic peaks corresponding to $\mathrm{Cd}$ and Te of the NPs and peaks from the L-cysteine ligand (C, S, and $\mathrm{O}$ ) were also observed, which confirm the elemental composition of the L-cysteinecapped CdTe NPs. Moreover, the average atomic percentage ratio of $\mathrm{Cd} / \mathrm{Te}$ is 1.87 , which indicates that the as-prepared NPs are enriched in cadmium.

The bonding between the stabilizer L-cysteine molecules and CdTe NPs was confirmed by the FT-IR measurement (Fig. 2). In the FT-IR pattern of the L-cysteine-capped CdTe NPs, the three

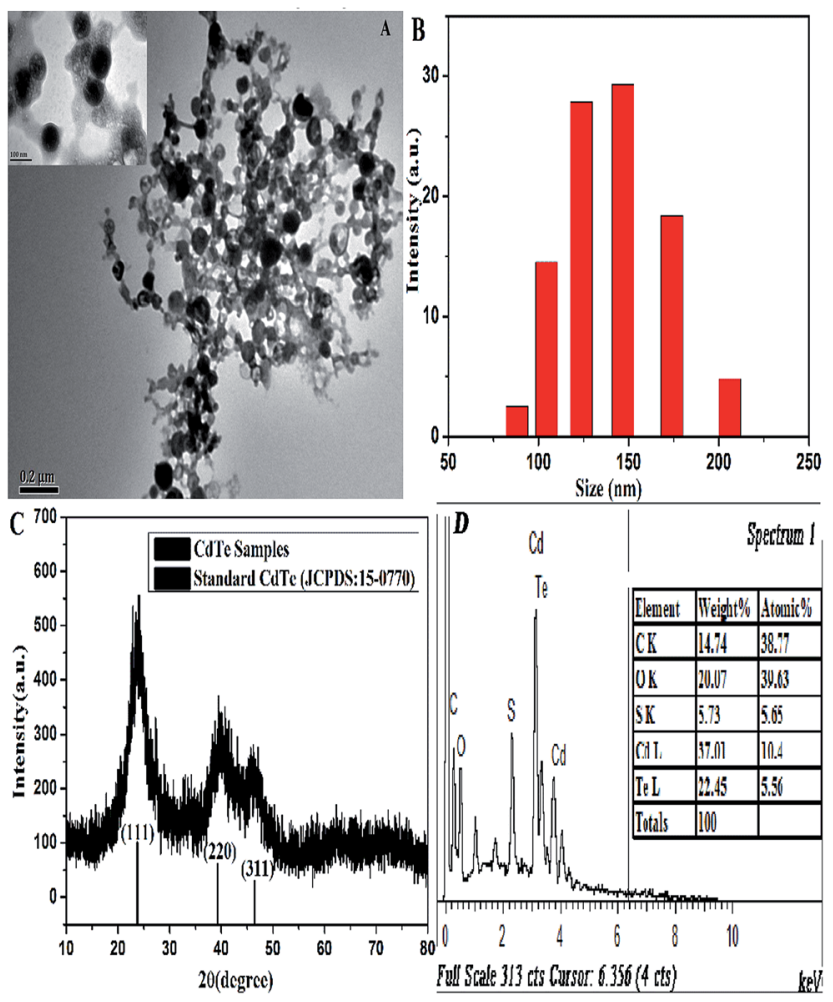

Fig. 1 (A) TEM image, (B) dynamic light scattering, (C) XRD pattern, and (D) EDS spectrum of the CdTe NPs.

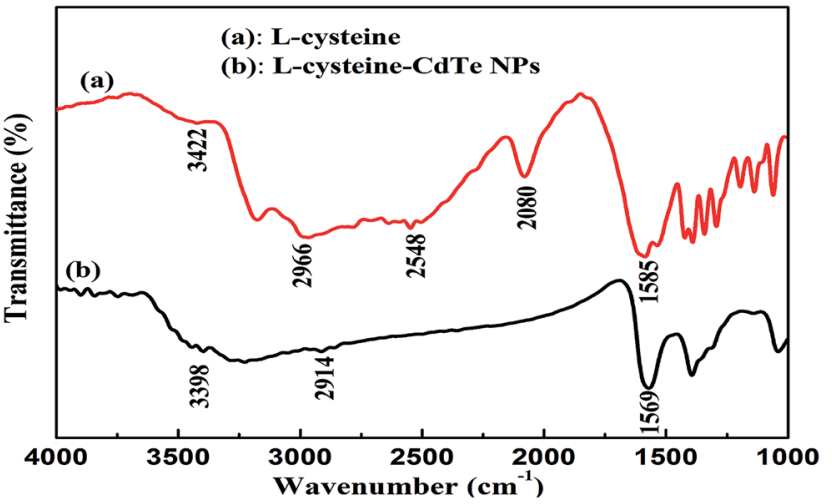

Fig. 2 FTIR spectra of (a) pure L-cysteine and (b) L-cysteine-capped CdTe NPs.

well-resolved peaks at $3402 \mathrm{~cm}^{-1}, 2914 \mathrm{~cm}^{-1}$, and $1569 \mathrm{~cm}^{-1}$ are assigned to the stretching vibration of $\mathrm{O}-\mathrm{H}$, anti-symmetric stretching of $-\mathrm{CH}_{2}$, and asymmetric stretching vibration of $\mathrm{COO}^{-}$, respectively. Compared to the FTIR absorption spectrum of pure L-cysteine, the characteristic peak at $2548 \mathrm{~cm}^{-1}$ (the stretching vibrations of $\mathrm{S}-\mathrm{H}$ ) completely disappeared, which is attributed to the cleavage of $\mathrm{S}-\mathrm{H}$ bonds and formation of $\mathrm{Cd}-\mathrm{S}$ bonds. This is because L-cysteine, which is a bifunctional ligand, can afford thiol groups to form a chemical bond with $\mathrm{Cd}^{2+}$ on the NPs surface. ${ }^{39}$ Furthermore, the absorption peak at $2080 \mathrm{~cm}^{-1}$ (the stretching vibrations of the $\mathrm{N}-\mathrm{H}$ of the $-\mathrm{NH}_{3}{ }^{+}$ group of L-cysteine) also disappeared due to the basification of the $-\mathrm{NH}_{3}{ }^{+}$group of L-cysteine during the synthesis. The abovementioned results reveal that L-cysteine was successfully modified on the CdTe NPs surface. The UV-visible absorption and fluorescence emission spectra were applied to describe the optical properties of the L-cysteine-capped CdTe NPs. As depicted in Fig. 3, the excitonic peak of the CdTe NPs appears at $547 \mathrm{~nm}$. Upon excitation at $328 \mathrm{~nm}$, the NPs display a narrow and symmetrical fluorescence emission peak at $570 \mathrm{~nm}$.

\subsection{Optimization of the detection conditions}

The fluorescence of the CdTe NPs was quenched by the addition of dithizone, and then recovered by the sequential addition of

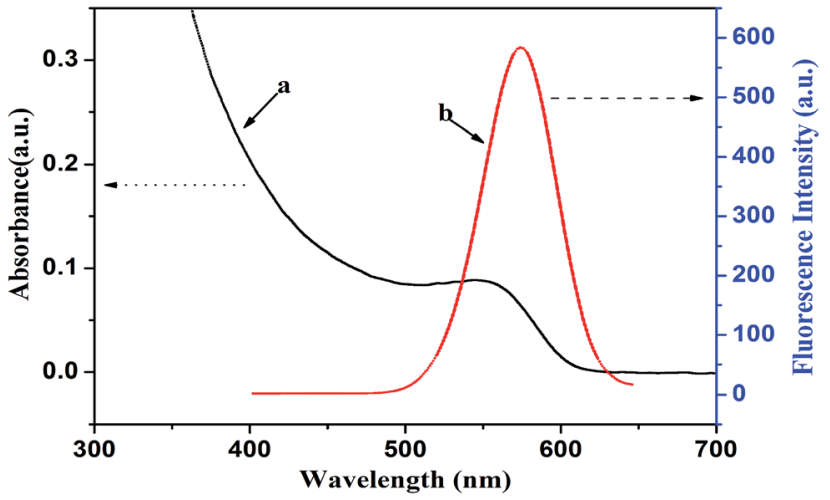

Fig. 3 (a) UV-vis absorption and (b) fluorescence emission spectra of L-cysteine-capped CdTe nanoparticles. 
$\mathrm{Cd}^{2+}$ (Fig. 4A). To obtain the optimal detection conditions, we investigated various possible influences on the detection. In this study, we first studied the effect of the reaction medium. Phosphate buffer, ammonium chloride-ammonia buffer, sodium acetate-acetic acid buffer with the same $\mathrm{pH}$ values, and ultrapure water were all investigated and the results are shown in Fig. 4B. It can be seen that whether the fluorescence is quenched by dithizone or restored by $\mathrm{Cd}^{2+}$, the fluorescence intensity is the best in ultrapure water, which may be attributed to the ionic strength effect. ${ }^{40}$ Therefore, ultrapure water was chosen throughout the experiment.

Reaction time also has an important influence on the fluorescence intensity as well as sensitivity of the system. As illustrated in Fig. 4C, the fluorescence of the CdTe NPs quickly decreased in the presence of dithizone and stabilized in $40 \mathrm{~min}$. Furthermore, the fluorescence recovery of the DZ-CdTe NPs system was accomplished in $40 \mathrm{~min}$. Thus, we chose $40 \mathrm{~min}$ as the optimal incubation time for further experiments. The effect of the concentration of CdTe NPs on the fluorescence response towards $\mathrm{Cd}^{2+}$ was also investigated and is displayed in Fig. 4D. It was found that the concentration of $0.20 \mu \mathrm{M}$ CdTe NPs generates the best enhancement results.
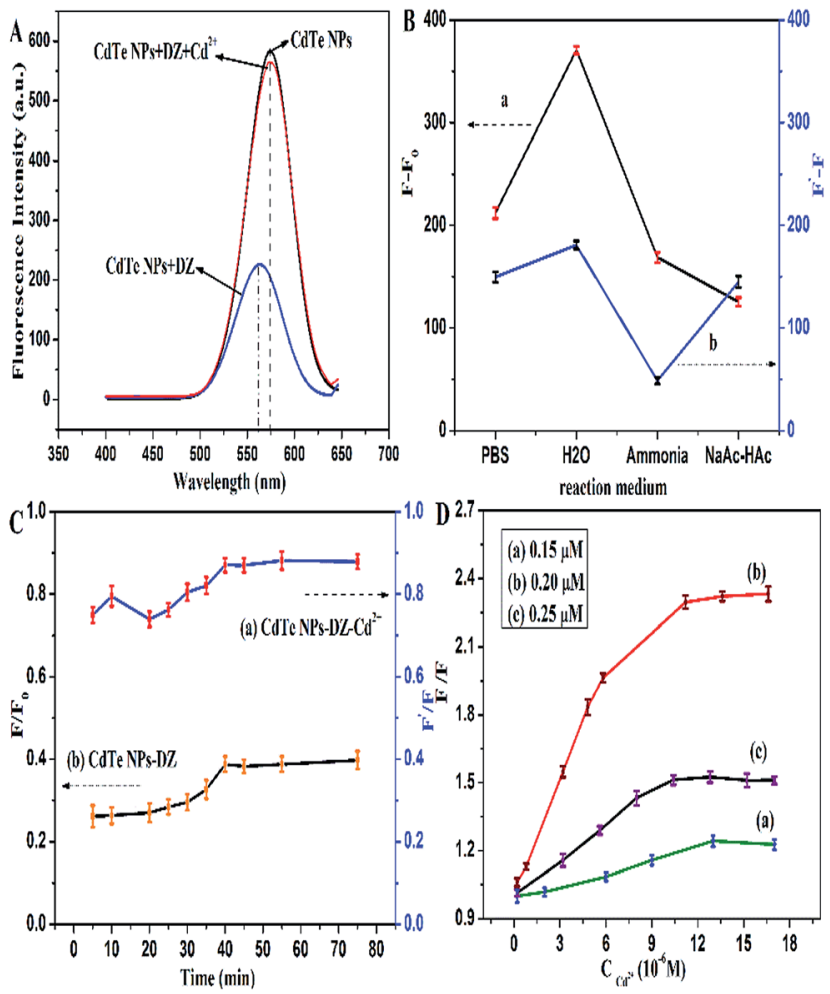

Fig. 4 (A) Influence of DZ and $\mathrm{Cd}^{2+}(15.4 \mu \mathrm{M})$ on the fluorescence of CdTe NPs. (B) (a) Fluorescence restoration of the DZ-CdTe NPs system by $\mathrm{Cd}^{2+}$ and (b) fluorescence quenching of the CdTe NPs by DZ in different media. (C) Effect of incubation time on the fluorescence intensity of (a) CdTe NPs-DZ-Cd ${ }^{2+}$ system and (b) CdTe NPs-DZ system. (D) Fluorescence response of different CdTe NPs concentrations containing the same amount of DZ $(44 \mu \mathrm{M})$ versus the concentration of $\mathrm{Cd}^{2+}$. Herein, $C_{\mathrm{NPs}}, C_{\mathrm{DZ}}$, and $C_{\mathrm{Cd}^{2+}}$ are $0.20 \mu \mathrm{M}, 38 \mu \mathrm{M}$, and 12 $\mu \mathrm{M}$, respectively, except stated otherwise.

\subsection{The quenching of CdTe NPs by DZ}

L-Cysteine, which is a thiol-capping reagent, could dramatically improve the stability and water-solubility of the CdTe NPs by forming a Cd-thiol complex around the surface of the NPs. Typically, this Cd-thiol complex surface layer occupies the surface sites and passivates the NPs to maintain high luminescence. However, dithizone (DZ), as a bidentate chelator, partly breaks these complex layers and removes $\mathrm{Cd}^{2+}$ on the surface of NPs. Then, the newly released $\mathrm{Cd}^{2+}$ combines with DZ, forming a new Cd-DZ complex. Hence, this partial loss of the Cd-thiol complex induced remarkable fluorescence quenching. As displayed in Fig. 5, with an increase in the DZ concentration, the fluorescence of the L-cysteine-capped CdTe NPs gradually decreases, and the quenching extent is dependent on the concentration of DZ. Moreover, a slight blue-shift (up to $11 \mathrm{~nm}$ ) is observed in the fluorescence spectrum after the addition of $62 \mu \mathrm{M}$ of DZ, which indirectly confirms the occurrence of a reduced diameter because of the absence of the Cd thiol complex around the surface of the NPs, which is in accordance with the size tuning fluorescence spectra of the NPs. ${ }^{37,39}$

Furthermore, there is a good linear relationship between $\log \left(F_{0} / F\right)$ and $\mathrm{DZ}$ concentration in the range of $8-62 \mu \mathrm{M}$. The regression equation is $\log \left(F_{0} / F\right)=-0.1171+0.01359[\mathrm{DZ}](\mu \mathrm{M})$ with a correlation coefficient of 0.998 (Fig. 5 , inset), where $F_{0}$ and $F$ are the fluorescence intensities of the L-cysteine-capped CdTe NPs in the absence and presence of DZ, respectively. The limit of detection (LOD) for DZ was found to be $2.7 \mu \mathrm{M}$ using the criterion of three times the standard deviation of the blank signal. In addition, we chose $38 \mu \mathrm{M} \mathrm{DZ}$ for the fluorescence restoration of the L-cysteine-capped CdTe NPs-DZ system induced by $\mathrm{Cd}^{2+}$.

\subsection{The fluorescence recovery of the CdTe NPs-DZ by $\mathrm{Cd}^{2+}$}

Accordingly, the addition of $\mathrm{Cd}^{2+}$ can result in the restoration of the fluorescence of the DZ-etched NPs since the introduction of

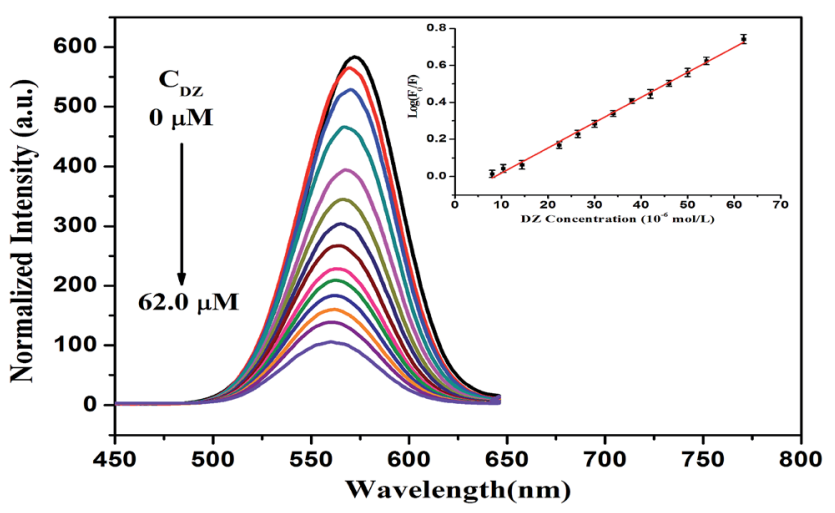

Fig. 5 Fluorescence spectra of the L-cysteine-capped CdTe NPs (0.20 $\mu \mathrm{M})$ upon the addition of different concentrations of DZ from 0 to 62 $\mu \mathrm{M}(0,8,10.4,14.4,22.4,26.4,30,34,38,42,46,50,54$, and $62 \mu \mathrm{M})$. The inset is the calibration plot of $\log \left(F_{0} / F\right)$ versus $D Z$ concentration $\left(F_{0}\right.$ and $F$ are the fluorescence intensities of the CdTe NPs in the absence and presence of $D Z$, respectively). 


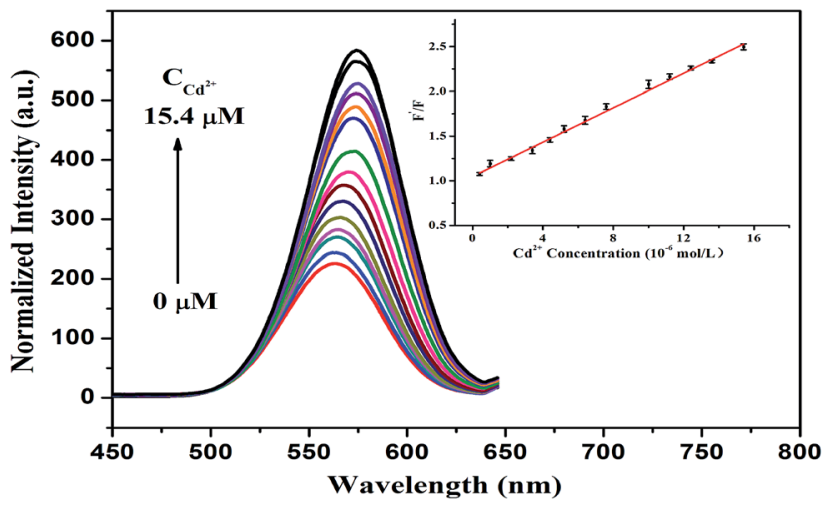

Fig. 6 Fluorescence spectra of the CdTe NPs $(0.20 \mu \mathrm{M})-\mathrm{DZ}(38 \mu \mathrm{M})$ system with the addition of different concentrations of $\mathrm{Cd}^{2+}$ in the range of $0-15.4 \mu \mathrm{M}(0,0.4,1.0,2.2,3.4,4.4,5.2,6.4,7.6,10,11.2,12.4$, 13.6, and $15.4 \mu M)$. The inset shows the relationship between $F^{\prime} / F$ and $\mathrm{Cd}^{2+}$ concentration ( $F$ is the fluorescence intensity of the CdTe NPsDZ system and $F^{\prime}$ presents the fluorescence intensity of the CdTe NPs-DZ system in the presence of $\mathrm{Cd}^{2+}$ ).

$\mathrm{Cd}^{2+}$ can repair the destroyed surface of the NPs by again forming the Cd-thiol complex. As demonstrated in Fig. 6, the fluorescence intensity recovery of the CdTe NPs-DZ system is proportional to the concentration of $\mathrm{Cd}^{2+}$ in the range from 0.4 $\mu \mathrm{M}$ to $15.4 \mu \mathrm{M}$. The linear regression equation (inset of Fig. 6 ) is $F^{\prime} / F=1.0495+0.0960\left[\mathrm{Cd}^{2+}\right](\mu \mathrm{M})$, where $F$ is the fluorescence intensity of the CdTe NPs-DZ system and $F^{\prime}$ presents the fluorescence intensity of the CdTe NPs-DZ system in the presence of $\mathrm{Cd}^{2+}$. The correlation coefficient was 0.999 and a low average relative standard deviation of $2.2 \%$ (ten repeats) was obtained. The limit of detection for $\mathrm{Cd}^{2+}$ is $0.13 \mu \mathrm{M}$ based on $3 S / K(S$ is the standard deviation of the blank signal of the CdTe NPs-DZ system $(n=10)$ and $K$ is the slope of the calibration line). Furthermore, we also compared this method with other reported methods for the detection of $\mathrm{Cd}^{2+}$. As listed in Table 1, it can be seen that the present method has a comparable detection limit and linear range.

\subsection{Mechanism of the CdTe NPs fluorescence switch}

To the best of our knowledge, it has been reported that DZ could efficiently quench the fluorescence of CdTe NPs by a FRET process because of the spectral overlap between the emission of the CdTe QDs and the absorption of the surface DZ-Cd complex. $^{45-47}$ However, poor spectral overlap between the

Table 1 Comparison of the present method with other fluorescent probes for the determination of $\mathrm{Cd}^{2+}$

\begin{tabular}{llll}
\hline Probe & Linear range & Detection limit & Ref. \\
\hline InP nanoprobe & $0.2-10 \mu \mathrm{M}$ & $0.1 \mu \mathrm{M}$ & 41 \\
T(4-NO 2 -P)P & $1.0-10 \mu \mathrm{M}$ & $0.276 \mu \mathrm{M}$ & 42 \\
MPA-CdTe QDs $^{a}$ & $1.3-25 \mu \mathrm{M}$ & $0.5 \mu \mathrm{M}$ & 43 \\
TG $^{b}-\mathrm{CdSe}$ QDs & $1.0-22 \mu \mathrm{M}$ & $0.32 \mu \mathrm{M}$ & 44 \\
L-Cys-CdTe NPs $^{-C}$ & $0.4-15.4 \mu \mathrm{M}$ & $0.13 \mu \mathrm{M}$ & This work
\end{tabular}

${ }^{a}$ Tetrakis(4-nitrophenyl)porphyrin, $\mathrm{T}\left(4-\mathrm{NO}_{2}-\mathrm{P}\right) \mathrm{P} .{ }^{b}$ Thioglycerol. emission spectrum of the CdTe NPs and the absorption spectrum of DZ-CdTe NPs system can be observed, as shown in Fig. 7A. Therefore, the fluorescence quenching of the CdTe NPs by DZ is not caused by FRET in this system. Herein, we propose a hypothesis according to previous studies. ${ }^{35,48}$ Upon the addition of DZ, the fluorescence of the NPs is apparently quenched probably due to the broken Cd-thiol complex surface layers. At the same time, $\mathrm{Cd}^{2+}$ on the surface of the NPs is removed, which accordingly creates specific $\mathrm{Cd}^{2+}$ recognition sites on the surface. The reaction here could be described as follows: ${ }^{35}$

$$
\text { CdTe@Cd-L-cys + DZ } \leftrightarrow \text { CdTe + L-cys }+\mathrm{Cd}(\mathrm{DZ})+\mathrm{Te}^{-}
$$

Since the specific $\mathrm{Cd}^{2+}$ recognition sites on the surface of the NPs could selectively bind $\mathrm{Cd}^{2+}$, upon the addition of $\mathrm{Cd}^{2+}$ into the DZ-etched NPs solution, the fluorescence of the DZ-NPs system is notably enhanced due to the re-passivation of the NPs on the surface. This is because some of the added $\mathrm{Cd}^{2+}$ could quickly relocate at the $\mathrm{Cd}^{2+}$ sites and the rest bond with the detached L-cys and remount on the surface of the NPs. The working principle of the designed sensor is shown in Scheme 1.

To further prove this hypothesis, we obtained the UV-vis absorption spectra and fluorescence spectra in the absence and presence of $\mathrm{Cd}^{2+}$. As illustrated in Fig. 7B, dithizone solution in ultrapure water shows three strong absorptions at $245 \mathrm{~nm}, 440 \mathrm{~nm}$, and $574 \mathrm{~nm}$. Upon mixing with CdTe NPs, the absorption peak of $\mathrm{DZ}$ at $574 \mathrm{~nm}$ disappears, whereas the
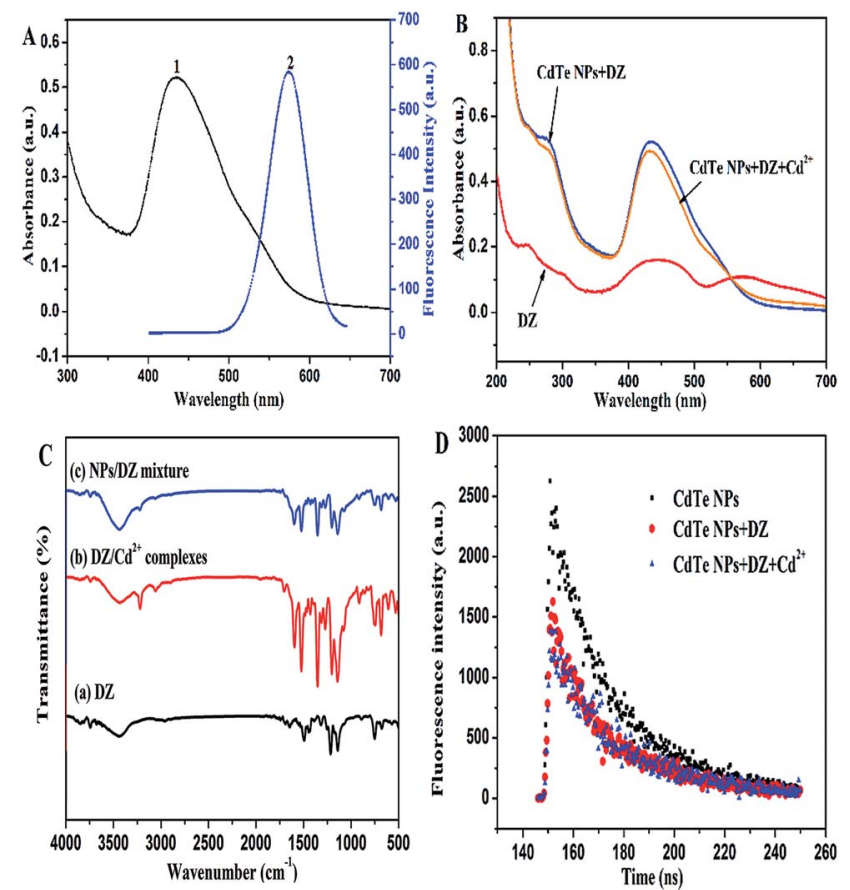

Fig. 7 (A) UV-vis absorption spectrum of the DZ-CdTe NPs system (1) and emission spectrum of the CdTe NPs with the maximum emission at $570 \mathrm{~nm}(2)$ and (B) UV-vis absorption spectra. The concentration of CdTe NPs, DZ, and $\mathrm{Cd}^{2+}$ was $16 \mu \mathrm{M}, 44 \mu \mathrm{M}$, and $12 \mu \mathrm{M}$, respectively. (C) FT-IR spectra of DZ, DZ/Cd ${ }^{2+}$ complexes, and NPs/DZ mixture and (D) fluorescence decay curves of CdTe NPs $(1 \mu \mathrm{M})$, DZ $(14 \mu \mathrm{M})$-etched CdTe NPs, and $\mathrm{Cd}^{2+}(4 \mu \mathrm{M})-\mathrm{DZ}$-etched CdTe NPs. 


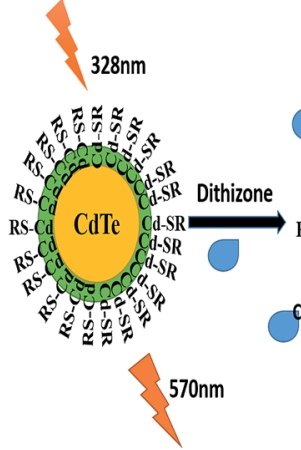

Strong Emission

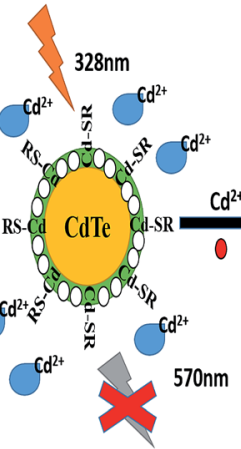

Fluorescence Off

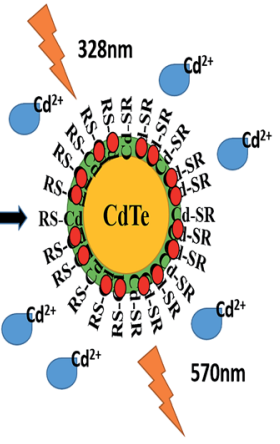

Fluorescence On

Scheme 1 Schematic of the selective fluorescence turn off-on detection of $\mathrm{Cd}^{2+}$ with dithizone-etched CdTe nanoparticles.

intensity of the peak at $440 \mathrm{~nm}$ is enhanced with a blue-shift (about $5 \mathrm{~nm}$ ) (Fig. 7B), which indicates the formation of a $(\mathrm{Cd}-\mathrm{DZ})_{n}$ chelate in the solution. Since the coordination between $\mathrm{DZ}$ and $\mathrm{Cd}^{2+}$ can reduce the atom number of the conjugated system, it leads to an increase in the electronic transition energy. ${ }^{49}$ Similar spectral blue shifts (up to $11 \mathrm{~nm}$ ) were also found in the corresponding fluorescence spectra of NPs-DZ (in Fig. 5). These variations show that DZ etched the surface of the NPs to release cadmium ions. However, upon the addition of $\mathrm{Cd}^{2+}$, the position of the peaks does not change, whereas the fluorescence of the DZ-etched NPs is recovered in conjunction with a red-shift in the emission spectra (Fig. 6). Note that the introduction of $\mathrm{Cd}^{2+}$ does not change the fluorescence of the unetched CdTe NPs (Fig. 4A). The above observed spectroscopic variations show a surface defect generation and repair process. ${ }^{50}$

Moreover, to further confirm the etching effect of DZ on the surface of the NPs, we obtained the FT-IR spectra and performed the PL lifetime measurements. FT-IR was mainly used to prove the formation of dithizone-Cd complexes in the mixture by comparing the FT-IR spectra of DZ, NPs/DZ mixture, and DZ/ $\mathrm{Cd}^{2+}$ complexes (see Fig. 7C curve a-c). As shown in curve a, the IR peaks of DZ at 3437.2, 2961.1, 1645.1, 1495.0, 1445.8, 1316.01000 , and $751.3-677.8 \mathrm{~cm}^{-1}$ correspond to $\mathrm{N}-\mathrm{H}, \mathrm{C}-\mathrm{H}$ (benzene ring), $\mathrm{C}-\mathrm{C}, \mathrm{N}=\mathrm{N}, \mathrm{N}-\mathrm{C}$ (the $\mathrm{C}$ of benzene ring), $\mathrm{N}-\mathrm{C}$ (the $\mathrm{C}$ attached to $\mathrm{S}$ ), and the vibration of the aromatic $\mathrm{C}-\mathrm{H}$ bending, respectively. For the $\mathrm{DZ} / \mathrm{Cd}^{2+}$ complexes, the consistent frequencies of the $\mathrm{N}-\mathrm{H}$ (adjacent to the aromatic ring), $\mathrm{N}-\mathrm{H}$ (adjacent to the $\mathrm{C}=\mathrm{S}$ functional group), $\mathrm{C}-\mathrm{H}, \mathrm{N}-\mathrm{N}, \mathrm{C}-\mathrm{C}, \mathrm{N}=\mathrm{N}$, $\mathrm{N}-\mathrm{C}$, and $\mathrm{C}-\mathrm{H}$ bending vibrations appearing in the experimental IR spectra are 3435.04, 3219.37, 3057.18, 1702.19, 1595.36, 1523.41, 1352.08-1000, and 914.38-690 $\mathrm{cm}^{-1}$, respectively. The shift in the absorption and existence of new absorption bands suggest the formation of $\mathrm{DZ} / \mathrm{Cd}^{2+}$ complexes. Furthermore, the FT-IR spectra of the NPs/DZ mixture is similar to the FT-IR spectra of the $\mathrm{DZ} / \mathrm{Cd}^{2+}$ complexes, thus indicating the formation of DZ-Cd complexes in the mixture, which also demonstrate that $\mathrm{DZ}$ etches the surface of the NPs to leak cadmium ions. In addition, the PL lifetime measurement was also performed to demonstrate the etching effect of $\mathrm{DZ}$ on the

NPs and the formation of passivation layers around the CdTe NPs. As presented in Fig. 7D, the fluorescence intensity signals of the NPs mono-exponentially decayed and the fluorescence lifetime of the NPs reduced from 24.3 ns to $20.3 \mathrm{~ns}$ after the addition of $14 \mu \mathrm{M}$ of DZ, which can be ascribed to the surface chemical etching of DZ around the NPs. ${ }^{51}$ However, the fluorescence lifetime of this NPs-DZ system increased from $20.3 \mathrm{~ns}$ to $22.7 \mathrm{~ns}$ because of the introduction of $4 \mu \mathrm{M}$ of $\mathrm{Cd}^{+}$, as shown in Fig. 7D. In previous reports, the surface passivation of nanocrystals with high bandgap materials (e.g. QDs) has been confirmed to be a perfect route to improve the PL efficiency and stability of the nanocrystals. ${ }^{52}$

Moreover, the etching effect of DZ on the NPs was also demonstrated by XPS characterization. As presented in Fig. $8 \mathrm{~A}(\mathrm{a}$ and $\mathrm{b}$ ), a new peak at $399.4 \mathrm{eV}\left(\mathrm{N}_{1 \mathrm{~s}}\right)$, appears in the XPS spectrum of the DZ-etched NPs, which is assigned to the nitrogen atoms in DZ, indicating that DZ is either bound to the surface or forms the DZ-Cd complexes in the solution. However, if DZ was bound to the surface of the material, the binding energy of $S_{2 p}$ should have been shifted to a lower binding energy due to the lower binding energy of the $\mathrm{S}=\mathrm{C}$ bond of $\mathrm{DZ}$ according to previous reports. ${ }^{47,53}$ On the contrary, as shown in Fig. $8 \mathrm{~B}(\mathrm{a}$ and b), the peak shape of $S_{2 p}$ of the DZ-etched NPs appears asymmetric and the major peak shifts to a high binding energy in our study, confirming that DZ is not bound to the surface of the NPs. Thus, DZ forms the DZ-Cd complexes in the solution.
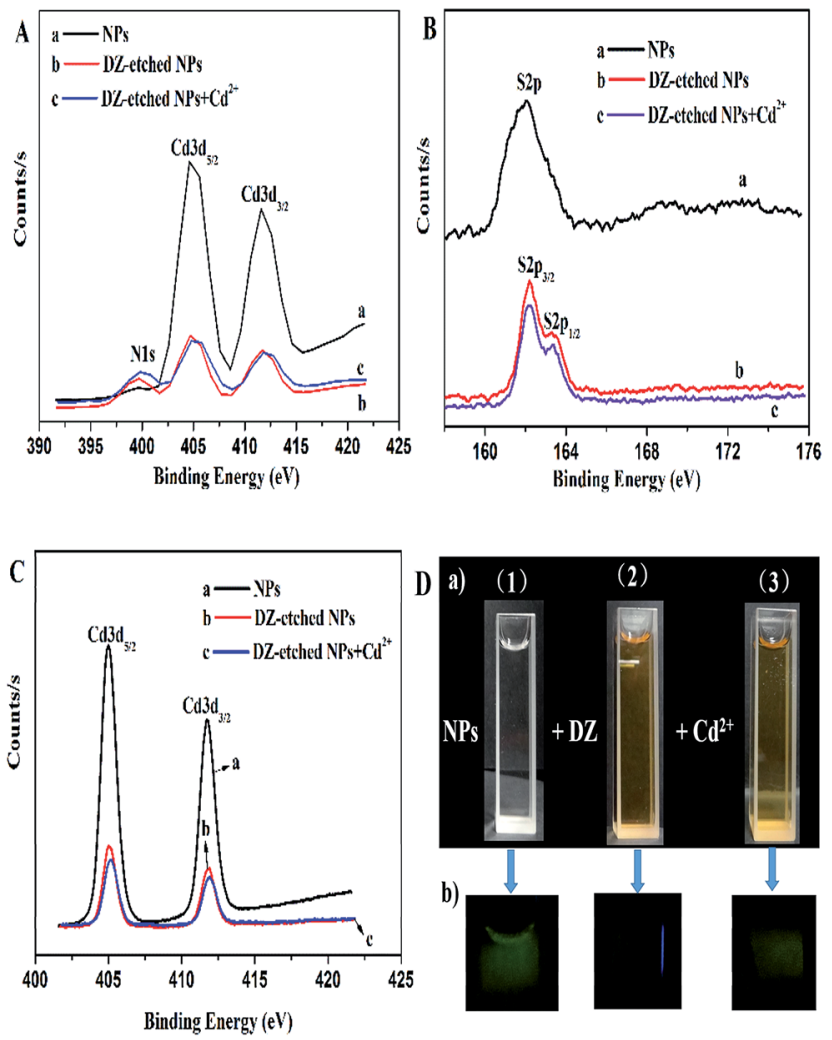

Fig. 8 (A) High-resolution $\mathrm{N}_{1 \mathrm{~s}}(\mathrm{~A}), \mathrm{S}_{2 p}(\mathrm{~B})$, and $\mathrm{Cd}_{3 d}$ (C) XPS spectra of the CdTe NPs, DZ-etched CdTe NPs, and $\mathrm{Cd}^{2+}-\mathrm{DZ}$-etched CdTe NPs. (D) Images of the CdTe NPs, DZ-etched CdTe NPs, and $\mathrm{Cd}^{2+}-\mathrm{DZ}$ etched CdTe NPs in water under visible (a) and UV light at $328 \mathrm{~nm}$ (b). 
Furthermore, the $\mathrm{Cd}_{3 \mathrm{~d}}$ spectrum of the NPs, as shown in Fig. 8C(a and b), shows the binding energy of Cd $3 \mathrm{~d}_{5 / 2}$ and $\mathrm{Cd}$ $3 \mathrm{~d}_{3 / 2}$ at $405.0 \mathrm{eV}$ and $411.7 \mathrm{eV}$, respectively. After the addition of $\mathrm{DZ}$, the binding energy of $\mathrm{Cd} 3 \mathrm{~d}_{5 / 2}$ remains unchanged, whereas the binding energy of $\mathrm{Cd} 3 \mathrm{~d}_{3 / 2}$ shifts from $411.7 \mathrm{eV}$ to $411.9 \mathrm{eV}$, which also demonstrates that DZ etches the surface of the NPs to destroy the Cd-thiol layers. To investigate the response mechanism of $\mathrm{Cd}^{2+}$ on the DZ-etched NPs, we also performed XPS measurements on the DZ-etched NPs before and after the reaction with $\mathrm{Cd}^{2+}$. After the introduction of $\mathrm{Cd}^{2+}$, the peak of $\mathrm{N}_{1 \mathrm{~s}}$, as shown in Fig. $8 \mathrm{~A}(\mathrm{~b}$ and $\mathrm{c}$ ), corresponding to nitrogen atoms in DZ, has no change and the high resolution spectrum of $\mathrm{S}_{2 \mathrm{p}}$ (Fig. 8B(b and c)) slightly shifts to a high binding energy. Furthermore, the $\mathrm{Cd}_{3 \mathrm{~d}}$ spectra (Fig. $8 \mathrm{C}(\mathrm{b}$ and $\mathrm{c})$ ) reveal that the binding energy of $\mathrm{Cd} 3 \mathrm{~d}_{5 / 2}$ shifts to $405.2 \mathrm{eV}$ from $405.0 \mathrm{eV}$, whereas the binding energy of $\mathrm{Cd} 3 \mathrm{~d}_{3 / 2}$ has no change. These data clearly show the formation of Cd-thiol layers, which is in agreement with the previous reports. ${ }^{54}$ Moreover, as could be seen in Fig. 8D, the color of the solution changed from colorless to light red, which also demonstrates the formation of coordination bond between $\mathrm{DZ}$ and Cd ions. Thus, the result of the XPS analysis is consistent with those of other analyses including UV absorption, FT-IR, and PL lifetime spectra.

\subsection{Interference study}

To evaluate the selectivity of the DZ-etched NPs as a turn-on fluorescent probe for $\mathrm{Cd}^{2+}$, we studied the fluorescence response of the CdTe NPs-DZ system in an environment with various relevant metal ions. As shown in Fig. 9, $\mathrm{Ni}^{2+}, \mathrm{Ca}^{2+}, \mathrm{Ba}^{2+}$, $\mathrm{Pb}^{2+}, \mathrm{Zn}^{2+}, \mathrm{Mn}^{2+}, \mathrm{Co}^{2+}, \mathrm{Sr}^{2+}, \mathrm{K}^{+}, \mathrm{Na}^{+}, \mathrm{Mg}^{2+}$, and $\mathrm{Cr}^{3+}$ did not produce any noticeable interference except $\mathrm{Ag}^{+}$and $\mathrm{Cu}^{2+}$. A 10.4 $\mu \mathrm{M} \mathrm{Ag}^{+}$and $\mathrm{Cu}^{2+}$ almost completely quenched the fluorescence of the unetched and DZ-etched NPs, which is probably due to the formation of non-radiative recombination pathways. ${ }^{55}$ However, thiourea might be an efficient masking agent to eliminate the interference of $\mathrm{Ag}^{+}$and $\mathrm{Cu}^{2+}{ }^{56}$

\subsection{Real sample detection}

The viability of the as-fabricated L-cysteine-capped CdTe NPsbased fluorescent sensor was evaluated in the determination
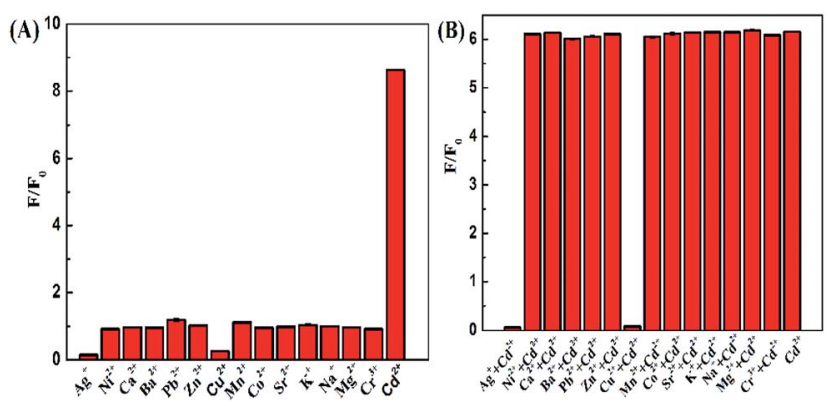

Fig. 9 (A) Ratio of the fluorescence intensity $\left(F / F_{0}\right)$ of the NPs $(0.20$ $\mu \mathrm{M})-\mathrm{DZ}(44 \mu \mathrm{M})$ system before $\left(F_{0}\right)$ and after $(F)$ the addition of various cations $(10.4 \mu \mathrm{M})$. (B) Relative fluorescence intensity $\left(F / F_{0}\right)$ of the NP $(0.20 \mu \mathrm{M})$ solutions containing $40 \mu \mathrm{M} \mathrm{DZ}$ in the presence of $6.0 \mu \mathrm{M}$ $\mathrm{Cd}^{2+}$ with the coexistence of $12 \mu \mathrm{M}$ of other cations.
Table 2 Real application of the fabricated fluorescence probes in water sample determination $^{a}$

\begin{tabular}{lcclc}
\hline Sample & $\begin{array}{l}\text { Added } \\
(\mu \mathrm{M})\end{array}$ & $\begin{array}{l}\text { Found } \\
(\mu \mathrm{M})\end{array}$ & $\begin{array}{l}\text { \% RSD } \\
(n=3)\end{array}$ & \% recovery \\
\hline Lake water 1 & 8.0 & 8.013 & 3.16 & 100.2 \\
Lake water 2 & 8.0 & 7.842 & 3.02 & 98.0 \\
Lake water 3 & 12.0 & 11.551 & 2.24 & 96.3 \\
Tap water 1 & 6.0 & 6.021 & 1.44 & 100.4 \\
Tap water 2 & 10.0 & 9.965 & 1.80 & 99.7 \\
Tap water 3 & 12.0 & 11.658 & 3.03 & 97.2
\end{tabular}

${ }^{a}$ All values are reported as mean of three measurements.

of $\mathrm{Cd}^{2+}$ in lake and tap water samples. From the results presented in Table 2, it could be seen that the average recoveries in the real samples vary from $97.21 \%$ to $107.60 \%$, and the relative standard deviation (RSD) is lower than 5\%, which suggest the validity of this method. Thus, the proposed sensor has good reliability for potential practical application.

\section{Conclusions}

In summary, we developed a novel and convenient method based on DZ-etched CdTe NPs for the determination of $\mathrm{Cd}^{2+}$ in aqueous media. Benefiting from simple, sensitive, and selective features, the as-prepared DZ-etched CdTe NPs work as an effective fluorescence sensor, showing a wide linear response range (0.4-15.4 $\mu \mathrm{M})$, low detection limit $(0.13 \mu \mathrm{M})$, good biocompatibility, and high selectivity for the quantitative determination of $\mathrm{Cd}^{2+}$. We believe that our findings present a possible approach for the future research on the design of highly sensitive biosensors.

\section{Acknowledgements}

This work was financially supported by the National Natural Science Foundation of China (NSFC) (No. 21271127, 61171033), the National Natural Science Foundation of China (No. 21271127, 21671132), and the Natural Science Foundation of Shanghai Municipality (No. 13ZR1415600).

\section{Notes and references}

$1 \mathrm{~J}$. P. Vernet, Heavy Metals in the Environment, Elsevier, New York, 1991.

2 J. Fu, L. Wang, H. Q. Chen, L. Bo, C. L. Zhou and J. G. Chen, Spectrochim. Acta, Part A, 2010, 77, 625.

3 D. M. Templeton and Y. Liu, Chem.-Biol. Interact., 2010, 188, 267.

4 X. Y. Xu and B. Yan, Sens. Actuators, B, 2016, 222, 347.

5 Y. Xue, H. Zhao, Z. J. Wu, X. J. Li, Y. J. He and Z. B. Yuan, Analyst, 2011, 136, 3725.

6 H. Xu, R. Miao, Z. Fang and X. H. Zhong, Anal. Chim. Acta, 2011, 687, 82.

7 A. Ismail, A. Kawde, O. Muraza, M. A. Sanhoob and A. R. AlBetar, Microporous Mesoporous Mater., 2016, 225, 164. 
8 S. Banerjee, S. Kar and S. Santra, Chem. Commun., 2008, 26, 3037.

9 A. M. L. Marzo, J. Pons, D. A. Blake and A. Merkoç, Anal. Chem., 2013, 85, 3532.

10 P. C. Huang, S. Li, N. Gao and F. Y. Wu, Analyst, 2015, 140, 7313.

11 B. S. Zhao, M. He, B. B. Chen and B. Hu, Spectrochim. Acta, Part B, 2015, 107, 115.

12 A. Islam, N. Zaidi, H. Ahmad and S. Kumar, RSC Adv., 2015, 5, 46662 .

13 X. F. Mao, Y. Zhang, J. X. Liu, M. Wang, Y. Z. Qian, Z. W. Zhang, Y. H. Qi and C. L. Gao, RSC Adv., 2016, 6, 48699.

14 A. O. Mehder, E. Yilmaz, A. Sungur, M. Soylak and Z. A. Alothman, At. Spectrosc., 2015, 36, 254.

15 H. X. Dai, N. Wang, D. L. Wang, H. Y. Ma and M. Lin, Chem. Eng. J., 2016, 299, 150.

16 M. Roushani, A. Valipour and Z. Saedi, Sens. Actuators, B, 2016, 233, 419.

17 N. Ruecha, N. Rodthongkum, D. M. Cate, J. Volckens, O. Chailapakul and C. S. Henry, Anal. Chim. Acta, 2015, 874, 40.

18 A. Sil, A. Maity, D. Giri and S. K. Patra, Sens. Actuators, B, 2016, 226, 403.

19 A. Visscher, S. Bachmann, C. Schnegelsberg, T. Teuteberg, R. A. Mata and D. Stalke, Dalton Trans., 2016, 45, 5689.

20 N. B. Brahim, N. B. H. Mohamed, M. Echabaane, M. Haouari, R. B. Chaabane, M. Negrerie and H. B. Ouada, Sens. Actuators, B, 2015, 220, 1346.

21 S. Y. Liu, Y. Y. Li and X. G. Su, Anal. Methods, 2012, 4, 1365. 22 Q. Zhao, X. L. Rong, L. Chen, H. B. Ma and G. H. Tao, Talanta, 2013, 114, 110.

23 R. Z. Zhang and W. Chen, Biosens. Bioelectron., 2014, 55, 83.

24 S. Liu, J. Tian, L. Wang, Y. Zhang, X. Qin, Y. Luo, A. M. Asiri, A. O. Al-Youbi and X. Sun, Adv. Mater., 2012, 24, 2037.

25 S. Huang, H. N. Qiu, F. W. Zhu, S. Y. Lu and Q. Xiao, Microchim. Acta, 2015, 182, 1723.

26 S. Y. Liu, J. J. Hu, H. Zhang and X. G. Su, Talanta, 2012, 101, 368.

27 L. Zhou, Y. H. Lin, Z. Z. Huang, J. S. Ren and X. G. Qu, Chem. Commun., 2012, 48, 1147.

28 Y. Song, Y. Li, Z. P. Liu, X. Y. Wang, X. G. Su and Q. Ma, Biosens. Bioelectron., 2014, 61, 9.

29 L. L. Wang, J. Song, S. P. Liu, C. X. Hao, N. X. Kuang and Y. Q. He, J. Colloid Interface Sci., 2015, 457, 162.

30 C. F. Zhang, Y. Y. Cui, L. Song and X. F. Liu, Talanta, 2016, 150, 54 .

31 M. J. Krysmann, A. Kelarakis, P. Dallas and E. P. Giannelis, J. Am. Chem. Soc., 2012, 134, 747.

32 V. Borse, P. Jain, M. Sadawana and R. Srivastava, Sens. Actuators, B, 2016, 225, 340.
33 H. L. Li, Y. W. Zhang, L. Wang, J. Q. Tian and X. P. Sun, Chem. Commun., 2011, 47, 961-963.

34 L. Shang, L. H. Zhang and S. J. Dong, Analyst, 2009, 134, 107.

35 P. Wu and X. P. Yan, Chem. Commun., 2010, 46, 7046.

36 L. Li, Y. Cheng, S. Q. Gu, F. F. Zhang and W. J. Yu, Eur. J. Inorg. Chem., 2013, 14, 2564.

37 W. W. Yu, L. Qu, W. Gao and X. Peng, Chem. Mater., 2003, 15, 2854.

38 A. H. Gore, D. B. Gunjal, M. R. Kokate, V. Sudarsan, P. V. Anbhule, S. R. Patil and G. B. Kolekar, ACS Appl. Mater. Interfaces, 2012, 4, 5217.

39 R. Kuang, X. Kuang, S. Y. Pan, X. D. Zheng, J. C. Duan and Y. Q. Duan, Microchim. Acta, 2010, 169, 109.

$40 \mathrm{H}$. Raghuraman and A. Chattopadhyay, Biopolymers, 2006, 83, 111.

41 Y. Zhang, Z. L. Zhang, D. H. Yin, J. Li, R. G. Xie and W. S. Yang, ACS Appl. Mater. Interfaces, 2013, 5, 9709.

42 R. Khani, E. Ghiamati, R. Boroujerdi, A. Rezaeifard and M. H. Zaryabi, Spectrochim. Acta, Part A, 2016, 163, 120.

43 H. Xu, R. Miao, Z. Fang and X. H. Zhong, Anal. Chim. Acta, 2011, 687, 82.

44 N. B. Brahim, N. B. H. Mohamed, M. Echabaane, M. Haouari, R. B. Chaâbane, M. Negrerie and H. B. Ouada, Sens. Actuators, B, 2015, 220, 1346.

45 S. G. Ge, L. Ge, M. Yan, X. R. Song, J. H. Yu and S. S. Liu, Biosens. Bioelectron., 2013, 43, 425.

46 K. Zhang, Q. S. Mei, G. J. Guan, B. H. Liu, S. H. Wang and Z. P. Zhang, Anal. Chem., 2010, 82, 9579.

47 Q. Zhao, X. L. Rong, H. B. Ma and G. H. Tao, J. Hazard. Mater., 2013, 250, 45.

48 R. J. Gui, X. Q. An, H. J. Su, W. G. Shen, Z. Y. Chen and X. Y. Wang, Talanta, 2012, 94, 257.

49 Y. M. Leng, Y. L. Li, A. Gong, Z. Y. Shen, L. Chen and A. G. Wu, Langmuir, 2013, 29, 7591.

50 Y. Zhang, Y. Li and X. P. Yan, Anal. Chem., 2009, 81, 5001.

51 J. Wang, C. X. Jiang, X. Q. Wang, L. G. Wang, A. M. Chen, J. Hua and Z. H. Luo, Analyst, 2016, 141, 5886.

52 B. O. Dabbousi, J. Rodriguez-Viejo, F. V. Mikulec, J. R. Heine, H. Mattoussi, R. Obter, K. F. Jensen and M. G. Bawendi, J. Phys. Chem. B, 1997, 101, 9463.

53 M. Stoev and A. Katerski, J. Mater. Chem., 1996, 6, 377.

54 H. Borchert, D. V. Talapin, N. Gaponik, C. McGinley, S. Adam, A. Lobo, T. Moller and H. Weller, J. Phys. Chem. B, 2003, 107, 9662 .

55 J. M. Costa-Fernández, R. Pereiro and A. Sanz-Medel, Trends Anal. Chem., 2006, 25, 207.

56 M. C. Rong, L. P. Lin, X. H. Song, Y. R. Wang, Y. X. Zhong and J. W. Yan, Biosens. Bioelectron., 2015, 68, 210. 